\title{
¿Qué medios para qué política y qué democracia?
}

\section{ENRIQUE GUINSBERG*}

\begin{abstract}
Resumen. Con base en el actual manejo mediático se analiza y discute el tema indicado en el título, considerändose que la idea de política $y$ de democracia que utilizan y a la que responden es casi exclusivamente la formal y electoral de las mismas, en consonancia con la ideología del poder boy begemónico, muy diferentes a otra forma de entendimiento de ellas. Luego de verse una serie de aspectos que dificultan o impiden que los actuales medios actúen a favor del fortalecimiento democrático-su cada vez mayor concentración, la priorización de formas de espectáculo, la mercadotecnia politica $y$, en algunos casos, el sistemático ataque a gobiernos elegidos democráticamente-, se plantean algunas observaciones de teóricos políticos y comunicológicos críticos en torno al papel de los medios para la democracia.
\end{abstract}

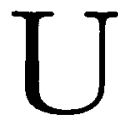

n importante conjunto de hechos produci-
dos en la cada vez más dinámica situa-
ción nacional y mundial ha renovado y replanteado la antigua discusión en torno a la relación y vínculos entre medios, política y democracia, problemática que en estas circunstancias asume un papel sustantivo ante el reconocido protagonismo mediático, pero con base en condiciones como el papel y limitaciones de los medios luego del 11 de septiembre de 2001, y la transmisión de videos en México en marzo de este año. Para su estudio se plantean los múltiples aspectos (viejos y nuevos) al respecto, con infinidad de interrogantes, cuestionamientos y polémicas en torno a esta problemática, con base en un importante conjunto de preguntas que se irán planteando y desarrollando en el presente ensayo y con el objetivo de promover el cada vez más indispensable debate al respecto.

- Especialista en psicología y comunicación. Universidad Autónoma MetropolitanaXochimilco. Correo electrónico: gbje1567@correo. xoc.uam.mx 
Por múltiples causas, el ejercicio actual de la política en el mundo entero es muy distinto al de no hace muchas décadas. Dichas causas son el peso cada vez más marcado del dominio del modelo económico neoliberal del mercado sobre los sentidos políticos, la incidencia de tal modelo impuesto por las instituciones financieras mundiales, la cada vez menor credibilidad y el mayor escepticismo de amplios sectores de la población en las actuales instituciones en general y en los partidos políticos y sus líderes en particular, las modificaciones culturales que se han producido en la presente época como producto de tal modelo y de la "posmodernidad" que ocasionan un importante descrédito de lo político, el peso presente de los medios masivos de difusión sobre el ejercicio político y la consecuente incidencia de la mercadotecnia electoral, etcétera. La política actual es así un campo donde se refleja el actual malestar en nuestra cultura.

En un ensayo con título muy gráfico Lechner sintetiza adecuadamente parte de esta realidad:

En América Latina, el régimen democrático es instaurado al mismo tiempo en que caen los regímenes comunistas y entra en crisis el Estado de Bienestar, en el que la sociedad de mercado logra un alcance global y se desarrollan nuevas formas de sociabilidad; es decir, tiene lugar en un momento histórico específico y no puede ser escindido de tal constelación. Pero al cambiar el campo en el que está inserta la democracia, también cambia la política democrática. A la par con el proceso de reestructuración que observamos en el nivel mundial y de cada país, tiene lugar una transformación de la propia política. La política ya no es lo que fue. En consecuencia, la imagen habitual que nos hacíamos de la política ya no es adecuada a las nuevas condiciones y, a la inversa, nos falta una nueva concepción de la política, capaz de dar cuenta de los cambios en marcha. A mi entender, el malestar reinante da expresión a esta situación [Lechner, 1997: 16-17, las cursivas son mías].

Todo esto trae modificaciones trascendentes para la politica, que de esta manera cambia su sentido de manera profunda, dejando de ser defensora $y$ propulsora de sus propuestas para convertirse en administradora con los escasos limites de autonomía indicados. Surge así una desideologización de los programas de los partidos o, peor aún, la presentación de programas que luego no se cumplen y que son conocidos sólo por quienes los formulan, que caen en promesas incumplidas con el consiguiente descrédito hacia ellos en particular y hacia la política en general, que han producido uno de los mayores niveles históricos de no credibilidad respecto a las instituciones en general, pero, sobre todo, en los partidos políticos y políticos por un conjunto de factores: vaciedad de propuestas y no creencia en ellas, juegos y maniobras políticas muchas veces evidentes, oportunismo de partidos y políticos, deshonestidad e impunidad, 
desmedidos gastos electorales, compra del voto 0 fraude electoral, acusaciones mutuas que en definitiva se revierten sobre la "clase política" en general, etcétera.

En cuanto a la "democracia" y su relación con los medios, Mouchon sintetiza de la siguiente manera una antigua polémica que hoy sigue vigente:

La parte que desempeñan los medios en el funcionamiento de la democracia contemporánea suscita numerosas cuestiones y alimenta un debate contradictorio en el seno de la comunidad científica. Se reivindican dos posiciones principales: una es esencialmente crítica y hace hincapié en las limitaciones impuestas por la lógica mediática a las formas clásicas de intercambio ciudadano; la otra, deliberadamente positiva, insiste en el vínculo consustancial entre los medios de masas y la apertura democrática. Apoyándose en datos empíricos, los autores de cada campo están de acuerdo en la necesidad de problematizar la reflexión [Mouchon, 1999: 13].

Esta reflexión, por la importancia del tema, no se limita a la comunidad científica, sino que se amplía al mundo político, periodístico y a muchos otros al reconocerse el fundamental peso actual de los medios masivos de difusión y su protagonismo (Guinsberg, 2004b), con las incidencias $e$ implicanciones que esto produce en todos los aspectos de la realidad sin excepción alguna. Este texto se suma a tales reflexiones, señalándose desde este mismo inicio que como parte de la señalada postura crítica con apoyo en los múltiples aspectos que se irán mostrando, y dejando explícito que, por considerarse aspectos suficientemente conocidos, se da por sentado el carácter central y prioritario de los medios para toda la vida y práctica política en el mundo presente.

El problema en torno a los medios y la democracia es, nada más y nada menos, qué se entiende por esta ültima, aspecto, por supuesto, central, pero que en la mayoría de los casos es soslayado pese a las críticas cada vez mayores que, desde muy diferentes ámbitos políticos e ideológicos, se hace a un término muy nombrado y respetado aunque incuestionablemente tiene un carácter polisémico, tanto en sus definiciones teóricas como, y sobre todo, en los hechos concretos de su realización, desde el conocimiento de lo que han sido los diferentes sistemas represivos, la caída del "socialismo real", los fracasos de las propuestas revolucionarias de décadas pasadas, y su aceptación por parte de muy diferentes sectores que elevaron su nombre, el de democracia, a un nivel casi mítico pero trás el cual pueden aparecer significaciones disímiles e incluso prácticas democráticas sólo de nombre para ocultar en ellas posturas contrapuestas e intereses muy concretos.

Pero frente a tal defensa, hoy más o menos generalizada dentro del campo político e intelectual, algo muy diferente ocurre en la mayor parte 
de la población mundial: según diferentes estudios y encuestas, una de ellas realizada por Naciones Unidas en Latinoamérica, $60 \%$ de los habitantes considera que la democracia es el mejor sistema de gobierno, pero otro $50 \%$ estaría dispuesto a apoyar a un régimen militar, si trajera solución a sus problemas económicos; o que del $60 \%$ que prefiere la democracia, la mitad estaría dispuesta a aceptar un régimen autoritario, si éste trajese solución a sus problemas económicos (La Jornada, 2003a: 11). Tal tendencia se ratifica cuando, según datos de Latinbarómetro 2002, en "Argentina y Paraguay se respondió a la pregunta: ¿qué tan satisfecho está con la democracia en su país? 'no muy satisfecho' y 'nada satisfecho', que en Argentina alcanza 96\%, mientras en Paraguay es de 98\%", ocupando México un tercer sitio con $81 \%$ (Oliva Posadas, 2002: 11).

\section{¿De qué democracia se habla?}

Se trata entonces de definir la propia esencia y el sentido de la democracia. En asociación libre se recuerda la famosa declaración de Churchill de que la democracia es el peor sistema de gobierno, excepto todos los demás. Pero, ¿hoy existe realmente democracia en las sociedades que dicen tenerla, o se trata, como escribe una connotada escritora, de "una vaca sagrada del mundo moderno" que

está en crisis? Y la crisis es profunda. Todo tipo de ultraje es cometido en nombre de la democracia. Se ha vuelto poco más que una palabra hueca, un lindo cascarón, vacío de todo contenido o significado. Puede ser lo que tú quieras que sea. La democracia es la Puta del Mundo Libre, dispuesta a vestirse y desvestirse, dispuesta a satisfacer una amplia gama de gustos, disponible para ser usada y abusada a voluntad [Roy, 2003: 7].

La afirmación es tan contundente como la realidad en la que se apoya. Nadie creía en la "democracia" de Saddam Hussein cuando ganaba las elecciones con $100 \%$ de los votos (a veces, incluso, con más), pero su uso es bastante más sutil y sofisticado en las sociedades modernas occidentales, donde se la reduce a sólo una práctica del voto una vez cada tantos años, sin importar mucho (o nada) que los electos hagan después lo que quieran con sus mandatos, incluso contradecir las propuestas por las que fueron elegidos, reiterar lo rechazado o gobernar con las mismas figuras de siempre pese a promesas de cambio que no se concretan. En esta perspectiva dominante, por supuesto que toda idea de democracia participativa -es decir activa, permanente y no limitada al voto en ciertos periodos- es considerada populista, revolucionaria o subversiva.

Tal idea de "democracia" es hoy la hegemónica y actúa como cobertura de la imposición del modelo neoliberal prevaleciente en la mayor parte 
del mundo. No es un mero detalle que uno de los creadores de este modelo, Friedrich Hayek, haya reconocido que "la democracia en sí misma jamás ha sido un valor central del neoliberalismo" (Kurnitzky, 1998: 27), algo convalidado en su imposición por regímenes no precisamente democráticos (Pinochet, Fujimori y otros) y el manifiesto apoyo al primero por Margaret Tatcher, uno de los epígonos de tal modelo.

A esto debe sumarse algo de fundamental importancia en consonancia con lo anterior: bajo las reglas de tal modelo - no escritas, pero vigentes de hecho-, quienes ejercen el poder económico son las instituciones financieras internacionales (Fondo Monetario Internacional, Banco Mundial y otras) y las grandes corporaciones transnacionales, quedando los gobiernos locales como ejecutantes políticos de tales decisiones en sólo variantes de tal modelo, pero sin capacidad de implementar uno opuesto o algo diferente. La realidad es, entonces, como gráfica y claramente lo señala un premio Nobel de Literatura:

No existe ninguna democracia. Ya no quiero ni llegar a lo que decía Abraham Lincoln, que la democracia es el poder del pueblo, por el pueblo y para el pueblo. Ya sabemos que no lo es y no lo ha sido nunca. Pero lo que pasa es esto: nosotros no vivimos en democracia, sino en un sistema plutocrático conformado por las corporaciones industriales y financieras que gobiernan el mundo. Nosotros estamos condicionados por ellas. Lo único que podemos hacer es quitar un gobierno y poner otro. Nada más. Todo el resto, que es lo que importa, se nos escapó de las manos [Saramago, 2003: 21].

O en palabras de la autora de un valioso best-seller.

En los últimos tiempos, muchos movimientos ciudadanos han tratado de invertir las tendencias económicas conservadoras eligiendo gobiernos liberales, laboristas o socialdemócratas sólo para descubrir que la política económica sigue siendo la misma, o que se somete más directamente aún a los caprichos de las empresas internacionales. Siglos de reformas democráticas que habían logrado crear gobiernos más transparentes se revelan de pronto ineficaces en el nuevo clima de poder multinacional. ¿Para qué sirven un Parlamento o un Congreso abiertos y responsables, si unas empresas impenetrables deciden tantas cuestiones de la política mundial en la trastienda? [Klein, 2001: 395].

Entre tantos ejemplos posibles de esto, ¿acaso no fue paradigmático el caso de Argentina, al ser De la Rúa elegido presidente por su manifiesta oposición y la de su coalición al modelo de neoliberal salvaje de Menem, para luego no sólo continuar con el mismo proyecto económico, sino también con el principal responsable de él durante el gobierno anterior? ¿De qué democracia se trata cuando se viola de tal modo la voluntad popular, y cómo no entender el repudio a ella por una población que se 
siente burlada? (y, por supuesto, de manera alguna es el único caso, como entre tantos otros lo demuestran Toledo en Perú, y lo fue el del derrocado Lozada en Bolivia)

¿Y cuál es la idea que se tiene de la democracia cuando a Aznar no le importó nada que millones de españoles se manifestaran contra la guerra que él apoyaba y $90 \%$ de la población lo expresara en las encuestas, así como en la Italia de Berlusconi y en Turquía y, en menor proporción, en Inglaterra y los mismos Estados Unidos en un comienzo? ¿Y debe recordarse la falta de respeto a tal idea de "democracia" cuando el poder de algún modo escapa a las elites tradicionales, que entonces sabotean al gobierno elegido de todas las maneras posibles e incluso apelan al golpe de Estado, como ocurrió en Chile hace 30 años o en Venezuela hace uno?

"Democracia", entonces, sólo de palabra, limitada a un voto en general respetado en cuanto la elección de dirigentes entre las variantes aceptadas de mantenimiento del statu quo, pero en las que no se sanciona a quienes no cumplen con las promesas ofrecidas, ni se respeta realmente la voluntad popular, como se muestra en el final del párrafo anterior. Se trata entonces, a la inversa de la clásica definición tradicional, "de una democracia de pocos, para pocos y con pocos" (González Casanova, 2003: 17), que no casualmente son siempre los intereses político-económico hegemónicos los que se intercambian entre sí, sin cambios centrales y a veces con los mismos hombres.

Sin duda, el ejemplo más notable al respecto es el de los Estados Unidos, el supuesto "paladín" de tal democracia en el mundo entero. Más allá de la fraudulenta elección de Bush en el 2000 y como lo destaca un conocido economista, se trata de

una situación sin precedentes de un sistema gobernado por un partido único de facto, el del capital. Los dos segmentos que conforman este partido comparten la misma forma fundamental de liberalismo. Ambos se dirigen sólo a la minoría que participa en esta forma de democracia truncada e impotente (representada en apenas $40 \%$ del electorado). Dado que la clase trabajadora, como regla, no vota, cada segmento del partido tiene su propia clientela de clase media para la cual adapta su discurso. Ambos han creado sus propios principios constitutivos, con base en un cierto número de los intereses de sectores capitalistas (los lobbies) y los grupos de apoyo comunitarios [...]. La democracia estadounidense constituye actualmente un modelo avanzado de lo que he llamado "democracia de baja intensidad". Su funcionamiento se basa en la total separación entre el manejo de la vida política, por medio de la práctica de la democracia electoral, y el manejo de la vida económica, regidas por las leyes de la acumulación de capital. Más aún, esta separación no tiene ninguna oposición radical, es parte de lo que podría considerarse un consenso general. Sin embargo, es esta separación la que destruye, efectivamente, todo el potencial creativo de la democracia política. Castra a las instituciones representativas (parlamentos y otros organismos), que se vuelven 
impotentes y sumisas ante el "mercado" y sus dictados. En este sentido, la alternativa de votar por demócratas o republicanos es irrelevante, pues lo que determina el futuro del pueblo estadounidense no es el resultado de sus decisiones electorales, sino los caprichos de los mercados financieros [Amin, 2003: 27].

Sin embargo, esta inmensa mentira ha sido creída no sólo por ciudadanos ingenuos, sino también por connotados intelectuales y politólogos que ven a ese país como "ejemplo de democracia" que debe ser seguida. Y seguramente para tales intereses lo es, pero no como modelo en tal sentido, sino por la capacidad de hacer creer en formas democráticas que no lo son, mas siempre sirven a claros intereses pero con el voto aprobatorio de las mayorias que aceptan su dominación y que mucbas veces creen, aunque no siempre, que están eligiendo y decidiendo sus destinos ${ }^{1}$. Hay que reconocer la capacidad que se ha tenido, a lo largo de mucho tiempo, de proyectar a nivel general la extremadamente cínica postura de un teórico publicitario acerca de que la publicidad tiene la función de lograr que las personas a quienes se dirige "hagan libremente lo que nosotros queremos que hagan" (Holzchuher, 1966: 54).

Por supuesto que el problema no es de la democracia, sino dęl uso que se hace de ella, algo que no parecen ver ni entender quienes la defienden sin querer comprender el porqué de un desinterés o rechazo cada vez mayor hacia la misma, que observan algunas deficiencias sin analizar las causas profundas, algunas de las cuales aparecen aquí señaladas. Claro ejemplo de esto puede verse en las diferentes posturas que se plantean en el tema central, "El desencanto por la democracia", en una revista que es claro exponente de este profundo vuelco hacia la "democracia" y que múltiples veces fuera presentada como afecta al gobierno mexicano del periodo 1988-1994 (Nexos, 2003), donde prácticamente nada de lo sustentado en este artículo es siquiera mencionado. Algo parecido, aunque no igual porque se plantean algunos cuestionamientos, puede verse en otra revista de tendencia similar, aunque con diferencias internas con la anterior (Letras Libres, 2004): aquí, su director escribe que "conquistamos la democracia pero no hemos sabido como habitarla" (Krauze, 2004: 24), reconociendo que todos sus protagonistas -incluida la prensa (que no cumple con lo que indica Amartya Sen que luego se transcribirá)no están a la altura de sus requerimientos, y proponiendo sobre esto la creación de un Comité de Opinión Pública, que en todo caso podría ser

\footnotetext{
' En los últimos tiempos es notorio un cambio en torno a esto, que va del notorio desinterés hacia los procesos electorales - caso del alto porcentaje de abstencionismo, algo ya clásico en México y otros países-, a una reacción activa contra gobiemos democráticamente elegidos como fueron, entre tantos otros; el caso de Argentina a fines de 2001 y parte de 2002, con la ya famosa consigna de "que se vayan todos" (aunque sin proponer ni encontrar una alternativa), la masiva rebelión boliviana que expulsó al presidente Lozada, y el absoluto y masivo repudio al presidente Toledo en Perú.
} 
no más que una especie de aspirina que poco cambia lo sustancial del problema. Pero lo sustantivo de este número para nuestro tema es el planteamiento del citado Sen (2004: 13), que reconoce "que la democracia tiene exigencias que van más allá de las urnas" y requiere de la discusión a la que más adelante se hará referencia.

Un último ejemplo sobre esto puede verse en una revista que dedica su número especial de abril de 2004 casi íntegramente al escándalo de los videos y al papel de los medios en ellos (Etcétera, 2004). También aquí se hace gala de la defensa de la "democracia", pero sin indicar en qué consiste, siendo mínimas las visiones críticas sobre su ejercicio real y, en una evidente toma de posición, haciendo una generalmente explícita condena al actual gobierno del Distrito Federal al de hecho negar la posible existencia del "complot" contra éste que él mismo denuncia (algo muy diferente a lo que puede observarse en otra publicaciòn mensual sobre los medios) (Zócalo, 2004). Si bien puede pensarse que esto último obedece a la fecha en la que aparece tal número, la misma actitud se reitera en el número de mayo, aunque algo, mínimo, se dice en su editorial pero sin darle mayor peso, lo mismo que en sus notas donde se mantiene tal condena casi absoluta. ${ }^{2}$

Queda entonces claro el sentido del título de este trabajo y la necesidad de precisión respecto de qué democracia se.habla, postula y defiende.

\section{Límites de la discusión democrática en los medios}

En un texto ya citado, el premio Nobel Amartya Sen considera que la democracia no puede verse sólo de manera restrictiva en términos del voto público, sino más ampliamente en términos de lo que John Rawls llama "el ejercicio de la razón pública, concepto más amplio que incluye la oportunidad de los ciudadanos para participar en las discusiones políticas y para estar en condiciones de ejercer influencia sobre la decisión pública" (Sen, 2004: 13), planteamiento que fundamenta señalando que

\footnotetext{
${ }^{2}$ No es éste el lugar para un estudio y análisis de esa revista, pero sí es necesario señalar que tal postura surge tanto de las características ideológicas (no explícitas) de la publicación y sus integrantes, como de la selección hecha de los articulistas de ese número, donde puede observarse la escasa presencia de miembros de una postura comunicológica realmente crítica, y la contraria de integrantes y/o partidarios del gobierno de 1988-1994. En este sentido, no puede dejar de señalarse que una de las columnas siempre presente, y de gran extensión, es la de quien fuera figura señera en prensa de ese gobierno, y que su fundador y anterior director es uno de los principales columnistas del diario Crónica, que en algunos de sus últimos números la misma revista reconoce como sistemático opositor al actual gobierno del DF, postura evidente en los números citados de Etcétera.
} 
Ignorar la centralidad del uso público de la razón para la idea de democracia no sólo distorsiona y limita la historia de las ideas democráticas, también distrae la atención lejos de los procesos interactivos a través de los cuales funciona una democracia y sobre los que ésta funda su éxito. El descuido de las raíces globales del uso público de la razón, que constituye una pérdida en sí mismo, conlleva la ruina de una comprensión adecuada del lugar y el papel de la democracia en el mundo contemporáneo. Incluso con la difusión del sufragio para los mayores de edad y las elecciones justas, la deliberación libre de censura es importante para que la gente sea capaz de determinar lo que debe exigir, lo que debe criticar y la forma en que debe votar [p. 18].

Es indudable que los medios pueden ser herramientas sustanciales para el desarrollo del proceso de conocimiento y debate en torno a todos y cada uno de los aspectos políticos, económicos y sociales, así como para la defensa de las candidaturas de quienes se proponen para su ejercicio. Pero aquí surge el interrogante de si, teniendo tal capacidad al ser una de las instituciones centrales, para muchos incluso la hegemónica, para los procesos de socialización, divulgación, etcétera, cumplen realmente con tal papel en la sociedad contemporánea y, por tanto, contribuyen a la consolidación de las formas democráticas que en general dicen respetar y defender. Como podrá verse en lo que sigue, no hay muchas razones para creerlo y sí para señalar lo contrario, lo que múltiples estudiosos afirman con base en diferentes aspectos, fundamentalmente los que se enumeran a continuación:

\section{Concentración mediática y pensamiento (casi) único}

Es evidente y notorio un desarrollo mediático cada vez mayor en todos los sentidos, y sobre todo en el campo electrónico que es por mucho el más accesible y utilizado por las amplias mayorías de la población mundial que lo han convertido en la principal vía de acceso a la información, contacto con la realidad, distracción, conocimiento, etcétera. Los canales existentes son múltiples y con una clara tendencia a un aumento incesante con base en un desarrollo tecnológico que parece borrar todo tipo de fronteras - materiales y técnicas - permitiendo el acceso a ellos de cada vez más amplios sectores sociales, sea en forma gratuita o con pagos en general no demasiado onerosos (aunque sí lo son para las amplias mayorías paupérrimas de la humanidad, que deben conformarse con las, de cualquier manera, amplias opciones de acceso libre). La variedad es muy amplia, con emisoras tanto generales como especializadas en determinados campos (deportivo, cultura general, entretenimiento...), con destino a también diferentes niveles sociales.

La imagen que presentan los medios es, entonces, de una gran pluralidad y con la intención de cubrir los intereses, gustos y deseos de prácti- 
camente todos los ciudadanos y de amplios sectores humanos (sociales, políticos, ideológicos, estéticos, de género). Pero eesta imagen es verdadera y real? La respuesta es categóricamente afirmativa para el establishment político y mediático hegemónico, que se apoya en tal cantidad de fuentes emisoras y las opciones de contenido que tiene el público emisor, y lo esgrime como prueba definitiva de pluralismo y la diversidad. Sin embargo, es claramente diferente para un amplio sector cuestionador y crítico que considera que se trata sólo de una apariencia que encubre la realidad de ser sólo múltiples variantes de igual o similar contenido, donde no tienen cabida las posturas antagónicas con la oficial hegemónica, o sólo en una medida que las convierte en insignificantes ante el peso abrumador de tal cosmovisión ideológico-política, y que resulta útil para hablar de una libertad de prensa y pluralismo desmentido en los hechos, pero que sirve para cubrir tal apariencia.

Esta perspectiva, que siempre existió en no pocos estudiosos e investigadores de los campos de la comunicación y político, es renovada para nuestros tiempos con el planteamiento de Ignacio Ramonet acerca de un pensamiento único absolutamente dominante, y que el autor describe claramente:

Atrapados. En las democracias actuales, cada vez más son los ciudadanos que se sienten atrapados, empapados en una especie de doctrina viscosa que, insensiblemente, envuelve cualquier razonamiento rebelde, lo inhibe, lo perturba, lo paraliza y acaba por ahogarlo. Esta doctrina es el pensamiento único, el único autorizado por una invisible y omnipresente policía de la opinión [Ramonet, 1998: 15].

Aunque puede ser más correcto hablar de un pensamiento (casi) único como reconocimiento de las valiosas, aunque reducidas, posturas críticas que existen y como diferenciación con regímenes totalitarios que impiden hasta esas escasas y minoritarias posturas contrapuestas a lo que tal autor considera como tal pensamiento único: "la traducción en términos ideológicos con pretensión universal de los intereses de un conjunto de fuerzas económicas, en particular las del capital internacional" (p. 15).

No es éste el lugar para reiterar lo conocido ni dar ejemplos acerca de la cada vez mayor concentración mediática a nivel mundial y nacional - muy entrelazados-, frente a ellos es reducido (aunque muy importante como expresión de voces diferentes y de ciertas perspectivas de resistencia) lo que pueden hacer medios disímiles como, entre otros, el diario La Jornada, la revista Proceso o Radio Educación, pero sí podemos remarcar el estado actual en palabras del mismo Ramonet años después:

Estimo que desde hace unos 15 años, a medida que se aceleraba la globalización liberal, ese "cuarto poder" iba perdiendo su función de contra-poder. Lo que hemos descubierto, al analizar la globalización, al estudiar de qué manera hoy se 
establecía un capitalismo de nuevo cuño, un capitalismo que ya no es meramente industrial, sino financiero, un capitalismo de la especulación [...] es que los medios de información dejaron de constituir un contra-poder [...]. En ese marco [en el que las empresas globales tienen un poder a veces más importante que muchos estados] se produjo una importante transformación de los medios de comunicación de masas. En el corazón mismo de la estructura industrial y de la propiedad económica de los medios. Globalmente, hoy día, los medios de comunicación pertenecen, cada vez más, a grandes grupos mediáticos que tienen también una vocación global, una vocación mundial [Ramonet, 2003: 1].

Vocación mundial, sigue expresando, con dos características: "se ocupan de todo lo que puede ser escrito, filmado y realizado por sonido, y además lo difunden por todo tipo de canales"; y son grupos mundiales y no sólo nacionales y locales, hiper-empresas que "son ahora actores centrales de la globalización económica" (p. 2).

Esta dupla control-intereses incuestionablemente es un formidable instrumento para el control social, que busca, y en importante medida logra la internalización de los requerimientos del actual modelo de dominación en los integrantes del marco social, es decir, buscando su aceptación a través de todo tipo de mecanismos psicosociales (Guiñsberg, Matrajt, y Campuzano, 2001; Guinsberg, 1987), para lo cual siempre se utiliza la construcción de un determinado "principio de realidad" y de una "agenda", el ofrecimiento de entretenimientos y diversiones que actúan como "calmantes" en el alivio de tensiones (Freud, 1976; Guinsberg, 2004a), el deporte, etc., es decir, que tal proceso se hace de manera conjunta a través del sistema informativo, pero, sobre todo, mediante múltiples formas culturales que buscan incidir en el nivel emocional de los receptores.

También es incuestionable que para esos propósitos no es tarea prioritaria la promoción y búsqueda de una real, fuerte y constante discusión en torno a todos y cada uno de los aspectos de la vida social, política, económica y cultural, sino todo lo contrario. En torno a esto tampoco hace falta insistir en lo también muy reiterado - sobre todo por el pensamiento en comunicación, aunque no exclusivamente- acerca del manejo tendencioso de los medios, que hace mucho no son de comunicación sino de difusión, aunque sin asumir nunca explícitamente este rol para un mejor logro de sus objetivos.

Pueden darse infinidad de ejemplos al respecto (una copiosa bibliografía abunda sobre esto); lo ocurrido luego del 11 de septiembre de 2001 ofrece una prueba contundente de ese tipo de manejo mediático, donde incluso de manera explícita se hizo un control intencionado al servicio de la política y los intereses hoy hegemónicos, con conocidos casos de censura de todo lo que se oponia, y se opone, al poder (Guinsberg, 2002a y 2003). Como siempre, es en circunstancias extremas donde mu- 
chas veces lo oculto se muestra (casi) al desnudo y en su verdadera magnitud.

Todo lo indicado muestra de manera muy clara cómo los medios masivos de difusión, si bien reúnen las características para hacerlo, contribuyen muy poco a lo que el premio Nobel Amartya Sen considera una contribución necesaria para un debate democrático y, en consecuencia, para la creación y fortalecimiento de una sociedad y vida realmente democráticas; es decir, que supere a la democracia en su aspecto sólo formal de consulta electoral cada cierto tiempo. Lamentablemente los aspectos siguientes, que actúan en consonancia con éste, refuerzan esta apreciación.

\section{Los medios como ámbito de debate o de espectáculo}

Sobre esto tampoco es necesario abundar mucho, tanto por una igualmente extensa bibliografía crítica (por ejemplo, y tal vez como caso contundente y extremo, Debord, 1999), como, y sobre todo, por la percepción que cualquier observador común del universo mediático (y por tanto, mucho más los comunicólogos, analistas políticos, etcétera) puede hacer de las absolutamente mayoritarias programaciones de los medios, en especial los electrónicos, cuya función central es la de entretener, divertir y ocupar el tiempo de ocio. Con base en un claro entendimiento de las "necesidades" de los receptores - por simple comprensión al formar parte de un determinado contexto, o por rigurosos estudios mercadotécnicos- el objetivo es ofrecer lo que éstos desean (Guinsberg, 1988: 133-148; 2002b) y asi obtener una mayor audiencia en beneficio de publicistas y propietarios de los medios, y de manera no precisamente secundaria, transmitir contenidos acordes con intereses ideológicos y políticos.

Por eso, y para evitar repetir cuestiones muy conocidas, es preferible tomar un muy reciente ejemplo contundente al respecto, donde de manera manifiesta un conocido comunicador y directivo de TV Azteca en el campo informativo lo reconoce, y por lo tanto asume de hecho cómo los medios electrónicos poco o nada contribuyen a la creación y fortalecimiento de una democracia en sentido real y no sólo electoral, al no permitir el necesario debate y análisis de las problemáticas existentes. Desde un inicio lo asume al señalar que

[...] nunca antes hemos tenido tantos medios de comunicación ni tanto público para esos medios. Y sin embargo, nunca antes el diálogo sobre los temas fundamentales de nuestro país tan alejado de nosotros. Quizás esta afirmación sea un lugar común, pero es correcta [Sarmiento, 2004: 30]. 


\section{Y luego ofrece su explicación:}

El problema es que la televisión es un pésimo vehículo para la difusión de los temas importantes de la sociedad. Quizá la posición de Giovanni Sartori, en su pequeña pero clásica obra Homo videns (1988, Taurus), sea extrema. El pensador italiano, después de todo, afirma que "la televisión modifica radicalmente y empobrece el aparato cognoscitivo del Homo sapiens". Pero no hay duda de que este medio es ideal para la expresión emocional o visual, pero no para el razonamiento abstracto, que requiere una discusión a fondo sobre los temas fundamentales de una sociedad.

Y pocos párrafos más adelante su opinión es categórica, afirmación que tiene una gran importancia por lo muy conocido del papel de la TV como medio hegemónico sobre la población y fuente de un muy alto porcentaje de información y conocimiento, lo que él mismo reconoce:

La gran pregunta que debemos hacernos hoy los mexicanos interesados en construir un debate sobre los temas fundamentales del país llo que por supuesto es válido para todas las sociedadesl es si podemos lograr que los modernos medios electrónicos, y en particular la televisión, que es sin duda el medio más ubicuo de todos, se conviertan en un foro de discusión prolongada e inteligente sobre los problemas más importantes de nuestro país. Pero la respuesta debe ser, me temo, un rotundo "no" [las cursivas son mías].

Consciente de la fuerza de esta afirmación, de inmediato el comunicador que escribe esta reflexión en una revista considerada (más allá de su orientación) seria y de nivel intelectual, defiende su postura y responsabiliza de lo anterior al público receptor:

Entiendo que cuesta trabajo aceptar eso. No faltan nunca ni los intelectuales ni los políticos que afirman que el problema es responsabilidad de los dueños de las grandes cadenas. Si éstos fueran más responsables, si estuvieran dispuestos a darle a la 'gente una televisión más inteligente, este medio podría realmente liberar el gran potencial de reflexión que tiene nuestro país. Sin embargo, la experiencia nos demuestra una y otra vez que el gran público, el que llega fatigado a casa después de un día de trabajo y ajetreo y se deja caer sobre un sofá enfrente de la televisión durante un par de horas, no tiene ningún deseo de ver programas que le generen un reto intelectual.

Refuerza este comentario al señalar que han sido muchos los esfuerzos "que se han hecho para crear una televisión inteligente", pero considera que los países europeos que durante largo tiempo mantuvieron una televisión pública que "daba a la sociedad programas de reflexión que contrastaban con el entretenimiento vulgar de las televisoras estadouniden- 
ses", al verse obligadas a abrirse a las emisoras más comeciales "la vieja televisión pública tuvo que transformarse para no ser despedazada". Y luego de enumerar varios programas que en México tratan los "temas fundamentales de la sociedad" - los ve como una oferta "bastante razonable"- valora que "la simple presencia, sin embargo, no significa que se esté logrando un alcance digno de la televisión: basta ver los ratings para entenderlo". Culmina su pensamiento en los párrafos finales también con señalamientos categóricos:

El político o el intelectual que realmente quiera tener éxito en las discusiones deberá entender que la televisión tiene reglas muy distintas a las de los medios impresos, el Congreso, los tribunales o las universidades. Quien, por ejemplo, desee discutir a fondo en la televisión el problema de la inversión privada en la electricidad, con todas sus complejidades y sutilezas, no logrará más que confundir a los televidentes. Un debate lo ganará quien logre evocar las imágenes más impactantes $u$ ofrezca las frases más contundentes, independientemente de su lógica [las cursivas son mías]. ${ }^{3}$

En su conclusión se reafirma todo lo anterior, responsabilizando otra vez al público de todo lo indicado y reiterando el escaso aporte de la televisión para una discusión seria.

¿Qué no deberían ser así las cosas? ¿Qué la televisión tendría que ser un instrumento de reflexión y de educación y no simplemente entretenimiento? Quizá. Pero el gran pecado que han cometido muchos políticos e intelectuales que han tratado de usar la televisión es que no han entendido ni al medio ni a su público. "Yo no tengo el poder: el poder lo tiene el televidente que prende, apaga o le cambia de canal al televisor", dijo Emilio Azcárraga Jean, presidente de Televisa, en una entrevista para la revista Lideres Mexicanos (diciembre 2001). Mientras esto no se compren$\mathrm{da}$, todos los esfuerzos por llevar los grandes temas de discusión a la pantalla resultarán infructuosos [las cursivas son mías].

La más o menòs larga transcripción de estos párrafos se hace por considerarla relevante respecto a este comunicador, en particular por su muy discutible idea de lo que es actualmente la TV y el papel que debe cumplir y, sobre todo, por constituir un claro testimonio de lo estudiado en el presente artículo y el aporte de los medios a la democracia (o en torno a lo que entienden por "democracia").

${ }^{3}$ Más allá de este evidente reconocimiento -que debe ser recordado cuando más adelante se haga referencia a la mercadotecnia electoral-, es importante tener en cuenta que tampoco en los medios impresos, y salvo en muy contadas excepciones, es posible encontrar un debate serio y fundamentado acerca de los grandes problemas. Lo mismo ocurre con mucha frecuencia en los ámbitos parlamentarios de gran parte del mundo. 


\section{La mercadotecnia política, la política y la democracia}

Hoy y desde hace ya un tiempo es un lugar común decir que política, medios y democracia forman una unidad total, que la política se hace en los medios y no puede prescindir de éstos, y que "hoy en día hablar de la lucha político-electoral en sistemas políticos de alternancia y competencia efectiva significa, en gran medida, hablar de estrategias de comunicación política"; esto porque "han llegado a constituirse en el principal vehículo de conocimiento del acontecimiento político; porque a través de ellos se gesta buena parte de las representaciones que nos formamos del devenir político y sus actores" (Arredondo, 1990: 11, 14-15), y también porque, en los últimos años, los medios de comunicación "constituyen los nuevos escenarios políticos donde se contruye el poder; la política se ha transladado de los lugares y las instituciones tradicionales al ámbito de los medios, especialmente en la televisión, dentro y fuera del género informativo" (Alfaro, 1994: 92). Más todavía,

[..] ya no son, si es que alguna vez lo fueron, un mero canal, sino que son, más bien, coproductores relativamente autónomos: no se limitan a "transmitir" la política ni a hacerla "agradable" sino que contribuyen a definirla y a menudo condicionan sus mismas modalidades de funcionamiento y de explicitación [Grossi, 1985: 153].

Cambio, sin duda, muy importante, con las transformaciones consiguientes en la misma política. Aquí, es necesario recordar dos cosas ya señaladas: primero, la llamada teoría de la agenda, y segundo, que la visión política no se limita a los programas específicos y a los noticieros sino que está presente, generalmente de manera implícita y no explícita, en toda la programación. Es lo que ya hace tiempo (1962) observó Cohen al escribir que "los medios masivos pueden no tener éxito buena parte del tiempo al decirle a la gente qué pensar, pero los medios tienen un éxito sorprendente al decirle a su público en qué debe pensar" (citado por Iyengar et al., 1986: 72).

Con tal subsunción de la política a los medios se produce un cambio radical en todos los sentidos; es decir, en la política y en los mismos destinatarios de ésta y de los mensajes: pasan de ciudadanos a consumidores, con una baja evidente y notoria en la calidad de los contenidos que se les envían, los que actualmente constituyen el centro de gravedad de las argumentaciones políticas en los que algunos consideran el momento más pleno de los sistemas "democráticos". Para Pratkanis y Aronson se trata de una situación donde

[...] el público, la prensa y los dirigentes políticos se encuentran atrapados en una espiral [...]. Una cobertura informativa muy sofisticada requiere un público que esté a su vez interesado y bien informado. Si no se cuenta con un auditorio 
instruido, los periodistas y los líderes políticos no tienen más remedio que simplificar el mensaje y hacerlo llegar envuelto en forma de "pasatiempo" o espectáculo, con lo que se reduce todavía más el grado de refinamiento del público en general. El resultado puede ser, tal como plantea Entman en el título de su libro, Una democracia sin ciudadanos [Pratkanis y Aronson, 1994: 302].

Si de acuerdo con esta opinión pareciera que medios y políticos tienen que "bajar" su nivel de discurso para poder ser escuchados, todo indica que la situación es mucho más compleja y menos lineal: desde hace ya mucho tiempo que se está produciendo esa notoria y evidente "baja" en la utilización, primero más lenta y después vertiginosa, pero siempre sólida, de mecanismos publicitarios cada vez más simples (desde el punto de vista del nivel argumentativo), aunque más complejos desde el punto de vista de la aplicación de reglas mercadotécnicas. No se trata de que el ciudadano elija con base en el pensamiento y la razón, sino de que el consumidor lo haga bajo el efecto y el impacto que llega esencialmente a sus deseos y fantasías inconscientes.

$\mathrm{Y}$, por supuesto, esto no es casual, sino buscado y en concordancia con todo lo ya explicado acerca de lo que se entiende por "política" y por "democracia" en el presente, y de cuya concepción no se quiere salir, tal como lo entiende claramente una investigadora:

Esta situación ha llevado a muchos a perfilar la ciudadanía en el exclusivo ámbito económico neoliberal. Entonces, comprar a crédito o participar en los procesos de venta y adquisición de las empresas del Estado, resulta ser un hecho ciudadano suficiente para reordenar la vida y la cultura de la gente. Se equipara ciudadanía con consumo, se le subsume dentro de un modelo económico específico. No se toma en cuenta otras aproximaciones que cuestionan tal banalización y despolitización de la esfera pública, pues ser ciudadano le otorga al sujeto un nuevo lugar y capacidad de reordenamiento de la sociedad y la política, incluyendo la creación de otro sistema económico mejor, si es voluntad y construcción puiblica [Alfaro, 1995: 110; las cursivas son mías].

Y esto último es lo que precisamente no se quiere que ocurra.

En este contexto y con tales significaciones de "política" y de "democracia" es que se produce el desarrollo, incremento y apogeo del marketing político-electoral. Según uno de los hoy múltiples investigadores sobre comunicación política (Grossi, 1985: 155-160) serían tres los modelos existentes sobre esto: el difusivo de la información política de Chaffee, que busca elevar los niveles cognoscitivos-informativos de los ciudadanos con el propósito de hacer más transparentes los mecanismos de decisión y entendiendo la relación de esto con la participación política (modelo que considero como de "excesivo optimismo iluminista"); el de la comunicación política como tematización, con base en los planteamientos de 
Luhmann, interesado en reducir la complejidad social a través de la evidenciación de temas, que sirven para captar la intención y la reducción de la incertidumbre; y el marketing político que será el que aquí se desarrollará y que se define como

un conjunto de técnicas expresivas y de estrategias psicológicas tendientes a imponer en el mercado político un personaje o un tema, a través de la confección de una imagen massmediatizada, ni más ni menos que como se hace con el producto de consumo en la publicidad [...]. [Y considera que] es la concepción que está en la base de la new politics de la era electrónica: los partidos políticos pretenden resolver sus propias contradicciones (pérdida de funciones, de representatividad, nuevas lógicas de voto, crisis de las subculturas de pertenencia) y/o aumentar al máximo sus propios resultados electorales aceptando una modalidad de comunicación política enteramente controlada y plasmada por los massmedia, y por tanto caracterizada por determinadas formas expresivas y orientada a subrayar predominantemente más el "significante" que el "significado" [Grossi, 1985: 155-160].

En una variante y precisión de la misma otro autor considera que

el marketing político debe ser entendido como el arte de la persuasión, que tiene como fin conseguir adhesiones para quien está o quiere estar en el poder y, al mismo tiempo, restarle fuerza e imagen al adversario [para lo que] se sirve del uso común y programado de técnicas de la comunicación, la publicidad, las relaciones públicas y la psicología [...] [Precisando más]. Desde la óptica del marketing político, el problema del poder se reduce a la cuestión de su conquista y mantenimiento por medio de la manipulación de la opinión. El marketing político busca seducir, no demostrar, o bien demostrar desde la seducción. El producto que ofrece es simbólico, es decir, se le pide al elector (consumidor) que vote (compre) por un candidato (artículo) intangible, o sea, se le está pidiendo que vote por promesas de satisfacción, que adquiera expectativas [...] [Y culmina citando a Morato]: "El marketing percibe a la sociedad en términos de mercado, y entiende que, si todo es relativo, pueden defenderse estos esteretipos, aquellas estrategias, estos candidatos o aquellas ideologías". Llevado a la actividad política, supondrá la percepción del electorado como un mercado en el que compite por la captación de un recurso finito, el voto, competencia a cuyos servicios se pone toda la estética que permiten las modernas tecnologias de la comunicación social [F. Chao Ebergenyi, 1997: 117].

Como puede verse, y en esto hay absoluta coincidencia, ni el nombre (marketing) ni los objetivos (venta, en este caso en el campo político), ni los métodos (similares a los publicitarios y hechos por éstos) son diferentes a los mercantiles clásicos, como lo recalca el director de la Revista Mexicana de Comunicación: 
Si el marketing comercial busca generar el consumo de cierto producto, el aplicado al ámbito político pretende estimular el consumo, la aceptación y la credibilidad de un determinado personaje o candidato. En otras palabras: se propone depurar y vender, con el apoyo de técnicas mercadológicas, una atractiva imagen de políticos en campaña o de gobiernos ávidos de credibilidad [Martínez, 1999: 5].

Se trata entonces, lo mismo que en los anuncios comerciales, de crear "una buena imagen que genere simpatías y convenza respecto de sus virtudes" porque, según una empresa especializada "la imagen determina la realidad" y $83 \%$ de las decisiones son tomadas en función de sentimientos y sólo $15 \%$ conforme a pensamientos. Por lo tanto, interesa lo concreto que se promete y proyecta, pero también el plano simbólico (generación de confianza, comprensión, solidaridad), la faceta física (rostro, vestimenta, lenguaje no verbal) y la faceta conceptual (formas expresivas y contenido del discurso).

Las diferencias entre el marketing y la comunicación política son evidentes: la segunda implica un quehacer de interrelación entre gobernantes y gobernados vinculado a la generación de información "que no se circunscribe a la mera venta de un producto político" con objetivos informativos-regulatorios, persuasivo-estratégicos y legitimantes-dialógicos. $\mathrm{Y}$ ante el retroceso notorio de esta comunicación el autor considera que "las opiniones, generalmente divergentes, coinciden en que la causa del déficit del discurso político radica en el exceso de la mercantilización de la vida política" (Vázquez Robles, 1998: 12-14), a diferencia de lo planteado en el comienzo de este capítulo y viendo la actual situación sólo desde la perspectiva de estos cambios comunicológicos y sin tener en cuenta las otras razones indicadas en este artículo.

De la misma manera en la que los publicistas comerciales reconocen muchas veces -en declaraciones, revistas especializadas e incluso artículos y libros- ${ }^{4}$ que trabajan como profesionales al servicio de los clientes que los contratan, y no dudan en reconocer sus tácticas y estrategias (sobre todo cuando son exitosas) donde poco o nada se informa sobre el producto, ahora que están de moda lo mismo hacen los publicistas en marketing. No es éste el lugar para un largo desarrollo al respecto (existe sobre esto una amplia bibliografía), por lo que sólo se citarán algunas declaraciones como representativas de la situación, para lo cual un muy buen ejemplo son las de Carlos Alazraki, uno de las principales exponentes de marketing en México y que ha llevado a cabo diferentes campañas -algunas exitosas y otras fracasadas, pero todas llamativas- en esa tónica; como por ejemplo cuando afirma que en su agencia ayuda a crear

${ }^{4}$ Como puede verse con múltiples ejemplos en mi libro Publicidad: manipulación para la reproducción, op.cit. 
la "perfección deseada del candidato y convencer a los que quieran comprar esa imagen y ese producto [...]. Para saber el impacto que tiene la publicidad, utilizamos las mismas técnicas del marketing de cualquier producto, aunque los políticos no lo quieran reconocer" (citado por Monsivais, 1997: 8). En esa línea considera que Madrazo (precandidato derrotado a la Presidencia de la República en elecciones internas del PRI a fines de 1999, pero con una campaña de fuerte impacto) "se ha vendido muy bien", reconoce que "yo disparo con bazookazos", no duda en afirmar que "en la publicidad política no hay ética" ni que "soy publicista, estoy haciendo publicidad y los candidatos son producto de consumo y la única diferencia en esta campaña es que, en lugar de comprar, la gente vota" (Alazraki, 1999: 5).

Otro interesante ejemplo lo ofrece Francisco Ortiz, Coordinador General de Mercadotecnia de la triunfante candidatura presidencial de Vicente Fox, quien explica los rasgos centrales de la misma, aunque considera que "se confunde mucho lo que es la utilización de la mercadotecnia como berramienta para transmitir un mensaje, con el ser un producto de la mercadotecnia en el peor sentido de la expresión", entendiendo que lo primero es lo que "por ejemplo, permite detectar cuándo el lenguaje político debe ser explicado en sus términos más sencillos". La labor del marketing sería entonces, para él, "tener la habilidad de traducir el lenguaje político en un lenguaje claro y directo" (Godinez, 2000: 15). Por supuesto, tales afirmaciones son muy discutibles, sobre todo, observan las características de una campaña que en su confección no difirió, en palabras de su propio dirigente, del marketing "en el peor sentido de la expresión".

Entonces, se trata de la utilización de técnicas publicitarias de fuerte impacto que no buscan apelar a la argumentación racional, salvo en pequeña escala, sino a los efectos emocionales con base en el estudio de las "necesidades" de los electores y tratando de llegar al "corazón" de éstos. Así, se reitera así lo tan conocido y estudiado en el campo publicitario ahora proyectado en el político, que Brünner recuerda: "el clásico hallazgo de Procter \& Gamble según el cual 'la publicidad alcanza su máxima efectividad cuando es irracional', en el sentido de que los productos pueden venderse mejor explotando los poderes mágicos e incluso poéticos del lenguaje y las imágenes", por lo que "la democracia empezaría a abandonar el marco de la razón comunicativa, donde inicialmente quiso colocársela, y se ubicaría cómodamente en el terreno de las emociones y las imágenes". Compartiendo la idea de que esto es por culpa de la comunicación y no por las otras causas indicadas, considera que "por obra del nuevo escenario comunicacional de la democracia, la propia política está obligada a transformarse en política-seducción" ya que, otra vez en conceptos de la agencia Procter \& Gamble, "una política, indistintamente de cuán buena sea, no tendrá éxito si no se vende bien" (Brünner, 
1997: 15-16). De este modo es como sistemas de comunicación de esta índole, donde "la forma cuenta ahora más que el contenido de lo que se muestra [...] puede hacer vibrar de emoción, pero ciertamente anestesia la razón" (Mouchon, 1999: 31, 36). Es por ello que un analista brasileño plantea un interesante paralelismo entre dos campos diferentes pero que coinciden en esto: "Collor tuvo una enorme sensibilidad política para captar cuáles eran las aspiraciones más simples de la mayoría de las novelas [se refiere a las telenovelas de Rede Globo, sistema que lo promovió] y, por eso, el contenido del discurso de Collor y el de las novelas tuviesen tantos puntos en común" (Lins da Silva, 1991: 59). ${ }^{5}$

Con tal base es que se apela - sea por conocimiento intuitivo de líderes o de caudillos que captan las emociones de los electores, o por las cada vez más sofisticadas investigaciones y mediciones psicosociológicas-, a las mencionadas necesidades, esperanzas y, sobre todo ahora, a las inseguridades y miedos - recuérdense, por ejemplo, su uso por Menem promoviendo el temor al retorno de la catastrófica inflación anterior y los riesgos para las compras a crédito, o la de Zedillo en 1994-, ya que "valerse del miedo es un recurso sumamente eficaz porque obnubila la mente e impide examinar con detenimiento la cuestión y pensar en la forma de desterrarlo" (Pratkanis y Aronson, 1994: 216). Estos mismos autores recuerdan una afirmación de Hitler respecto a la propaganda en su Mein Kampf que sigue en uso e incluso intensificada por el peso de unos medios electrónicos mucho más poderosos:

En buena medida, su efecto debe apuntar a las emociones y tan sólo en un grado muy limitado al llamado intelecto. Hay que evitar recurrir en exceso al razonamiento lógico de nuestra gente. La receptividad de las grandes masas es muy limitada, su inteligencia escasa, pero, en cambio, tiene una enorme capacidad para olvidar las cosas. Como consecuencia de todo ello, la propaganda efectiva debe ceñirse a unos cuantos puntos y machacar estos eslóganes hasta que el último ciudadano de una audiencia entienda qué es lo que queremos que comprenda con ese eslogañ que le proponemos [Pratkanis y Aronson: 339].

Quizás el ejemplo máximo actual sobre esta capacidad es que la mayoría de la población mundial acepta las premisas de un modelo hegemónico neoliberal que le produce las conocidas consecuencias negativas en los campos económicos, políticos, sociales y psíquicos haciéndole triunfar en las elecciones y buscando escasamente una alternativa.

3 El autor prefiere esta hipótesis frente a la de que tal cadena difundía dos exitosas telenovelas - ¿Qué rey soy yo y El salvador de la Patria - "tendría como objetivo el de inducir al elector de forma subrepticia al apoyar al candidato Collor", creyendo que "el maquiavelismo de Roberto Marinho [propietario de Rede Globo] puede ser inmenso, pero es improbable que llegue a esas exageraciones". Aunque no parece tan improbable. 
En México, un autor (Valdez Zepeda, 2000: 7-12) defiende el uso y las ventajas de la mercadotecnia, considerando que "su vigencia está estrechamente ligada al proceso mismo de cambio político, con sentido democrático", porque en México está ligado al aumento de competitividad y diversificación de los actores políticos, ayuda a incrementar el nivel de información y "a emocionar y movilizar a los electores que luchan por causas justas, como por el combate a la corrupción o a favor de la democracia", y busca como objetivo central la legitimidad social y el ascenso al poder mediante el voto popular.

En tal sentido, mercadotecnia y legitimidad política, a través de medios pacíficos y democráticos, aparecen como parte de un binomio indisoluble, ya que sólo regímenes políticos autoritarios o totalitarios se legitiman a través de la violencia, la imposición y el autoritarismo, más que por medio del apoyo, en un marco de libertad y respeto al estado de derecho de la ciudadanía.

Como parte de la crítica a quienes cuestionan la mercadotecnia, Valdez Zepeda reconoce que "es una herramienta al servicio de las clases políticas, pero también le es útil a la ciudadanía porque no tiene preferencias ideológicas", y destaca en su defensa:

Finalmente es importante apuntar que la mercadotecnia es mucho más que corsé, gesticulaciones, imagen, simbolismo, eslóganes y anuncios propagandísticos. El objeto central de su preocupación es el conocimiento y persuasión de los ciudadanos constituidos en mercado político. Investiga sus principales problemas como ente social; indaga su sensibilidad a los estímulos, analizando sus reacciones, sentimientos y comportamientos; diseña las estrategias propagandísticas más efectivas para lograr su cometido; estudia el contexto y la coyuntura política; establece relaciones entre mensaje, percepción y persuasión; se preocupa por los problemas asociados a la imagen y la opinión pública, así como de las acciones proselitistas de las elites políticas; penetra en la doctrina y las teorias políticas e investiga los fenómenos de la comunicación política.

Ejemplo interesante porque el autor, profesor del Departamento de Mercadotecnia de la Universidad de Guadalajara, no niega ni oculta muchos de los riesgos señalados por otros investigadores y que él también destaca: manipulación, falseamiento de informaciones, impostación de personalidades, sobreoferta política, superficialidad de planteamientos, creacion de escenarios falsos, etcétera. Pero entiende que a pesar de tales riesgos que la mercadotecnia implica para el proceso de transición política con sentido y rumbo democrático, "esta nueva disciplina está muy ligada a la existencia de una sociedad plural, donde diferentes actores políticos, regidos por un marco normativo, se disputan la voluntad del electorado". Por lo que, para preservar su utilidad frente a los abusos que no niega, plantea que 
el reto más importante de esta disciplina se reduce a su uso adecuado y moderado, estrechamente en relación con las pautas éticas de la sociedad y en concordancia con los principios de libertad, equidad y racionalidad que deben prevalecer en una democracia moderna; es decir: el reto más importante es hacer de la mercadotecnia política una disciplina al servicio de la democracia.

Sin embargo, no dice cómo ni tampoco valora en su real dimensión el peso cuantitativo y cualitativo de unos riesgos que han marcado y le dieron su sentido a la mercadotecnia.$^{6}$ En este sentido, y con vista en las evidentes contradicciones y falseamientos respecto a la realidad que se postulan y defienden en esos planteamientos, vale la pena reiterar lo escrito hace años (Guinsberg, 1987: 26-27) respecto a la publicidad luego de enumerar las críticas que se le hicieron desde múltiples ámbitos (teóricos como Vance Packard, algunos publicitarios, la Iglesia, etcétera), y que son válidos para este caso, por lo que su nombre reemplaza el término publicidad del original:

Vale aquí recordar el señalamiento de Marx respecto a la fuerza y debilidad de esa crítica que sabe juzgar y condenar el presente, pero no lo comprende, para apuntar que las anteriores observaciones pseudocríticas acerca de la mercadotecnia se dirigen en todos los casos hacia los efectos observados, sin analizar las causas que los provocan, que van mucho más allá de falseamientos éticos y morales. Ocurre que buscar y encontrar tales causas produce indefectiblemente un juicio crítico a la mercadotecnia en sí, objetivo muy diferente al buscado por sus defensores. Es de reiterar entonces que tales efectos difícilmente puedan ser evitados al ser intrínsecos a la actual función de la mercadotecnia, que necesita de la manipulación para cumplir con su rol, pudiendo señalarse sin duda alguna, que la eliminación de esos efectos implicaria la desaparición de la mercadotecnia.

Claro combate a la democracia (en nombre de la democracia)

La brevedad de este apartado es porque, por su evidencia, sólo requiere ser mencionado. Se trata de los lamentablemente numerosos casos en los que los medios son portavoces o actores directos del combate o búsqueda del derrocamiento de gobiernos democráticamente elegidos, pero que

6 Tal autor luego ha colaborado en muchas publicaciones, siempre en defensa de su postura. Excelentes síntesis de su planteamiento pueden verse en Valdez Zepeda (1999 y 2002), y junto con Ibarra (2004), y siempre, aunque ello sea negado, aparecen de manera absoluta y categórica las características indicadas de la mercadotecnia con su importancia en la imagen, el manejo de los sentimientos, etc. Véase, tal como se indica en el texto, que considera que la misma es consustantiva a una "democracia" que, por supuesto y aunque no lo dice, tiene las características que aquí se cuestionan y critican. 
no responden a los lineamientos del poder hegemónico. Entre tantos ejemplos se puede citar el caso del Chile de Salvador Allende en el periodo 1970-1973, donde el diario El Mercurio junto con otros y varias emisoras de radio y televisión fueron los arietes de los intereses opuestos al proceso de cambio, y luego los defensores a ultranza de la dictadura militar pinochetista; medios que incluso hoy no han hecho ni siquiera una mínima autocrítica y, a veces en nombre de la necesidad de "reconciliación" y "no mirar al pasado sino al futuro", siguen defendiendo a los violadores de la democracia y los derechos humanos al justificar el castigo a los mismos, Similar situación se produjo en Argentina en los periodos 1966-1973 y $1976-1982$.

En nuestro continente latinoamericano eso se reproduce desde hace varios años en Venezuela y continúa actualmente, donde las grandes cadenas televisivas -incluidas las internacionales como Fox y CNN entre otras - han hecho un bloque de fuerte oposición al gobierno de Hugo Chávez, promoviendo y convalidando el breve y provisorio golpe militar de 2003. Esto está muy documentado y es muy conocido, por lo que es innecesario abundar al respecto.

Una última mención, y muy actual, es respecto al papel que desempeñan los medios estadounidenses (incluyendo sus poderosas empresas interancionales), sobre todo los electrónicos, luego del 11-S al convalidar y aceptar tanto la censura oficial y la autoimpuesta, como las normas legales gubernamentales del Acta Patriótica en la llamada "lucha contra el terrorismo", postura que se mantuvo durante la invasión a Irak y que continúa actualmente. También de esto se ha hablado mucho y está muy bien documentado como para abundar al respecto. Pero, sí es importante reiterar cómo tras estas posturas puede verse nítidamente una idea muy clara respecto a qué se entiende por "democracia" y el papel y poder de los medios.

\section{Los riesgos para la política y la democracia}

¿Los profundos cambios indicados ayudan o son un riesgo para el desarrollo de las formas democráticas defendidas por el actual modelo hegemónico? Por supuesto, existe una amplia polémica al respecto, donde, como se vio, un conjunto importante de analistas tienen juicios críticos, mientras que políticos y publicistas piensan lo contrario. Es entonces importante terminar este artículo con una evaluación del problema y con una importante y fundamental aclaración: no se repetirá aquí lo planteado al inicio respecto a lo que entienden por democracia muchos de sus defensores, pues la limitan a su ejercicio formal, es decir a la existencia de voces $y$ partidos diversos, procesos electorales limpios, existencia de libertades públicas, etcétera, lo que por cierto es cuestionado por quienes consideran 
que la democracia es mucho más que eso. Pese a esto, es igualmente interesante observar cómo incluso los defensores de tal democracia formal consideran que el actual empleo de los medios de difusión y de la mercadotecnia la ponen en riesgo.

La discusión no es nueva, es anterior al actual desarrollo de la mercadotecnia política. Un claro ejemplo de ello es una crítica que, desde su mismo título y publicación a mediados de los setenta con respecto a los Estados Unidos, pero obviamente no limitado a él, señala que en gran parte "como resultado de sus efectos culturales más generales, la TV está diluyendo la base de experiencia y de información de la cultura política norteamericana y que, por consiguiente, está alterando la índole y la efectividad de la democracia norteamericana" (Manheim, 1983: 252). El autor se apoya en un conjunto de proposiciones: 1) el aprendizaje político en condiciones de baja implicación psicológica facilita la manipulación y reduce la comprensión cognitiva de su conducta; 2) la participación se reduce como consecuencia del cada vez mayor desinterés por la política; 3) un número en aumento constante se orienta e informa políticamente por la televisión ("un medio que les está dando menos y menos"); 4) la estructura misma de la TV "requiere un nivel relativamente bajo de participación en el acto de recibir la información", y 5) la reducción de la información compleja y el aumento de la confianza en la TV producirá un descenso psicológico: se sentirá una necesidad menor de participación, disminuirá la capacidad de realizar un procesamiento complejo de tal información, y bajará la capacidad de apreciar la complejidad de la política misma. Las conclusiones son muy fuertes:

El resultado será una constante reducción cualitativa del contenido intelectual del discurso político entre la masa de ciudadanos norteamericanos, lo cual puede hacer que una elite que conserve de manera más efectiva el conocimiento, las capacidades y los recursos requeridos, venga a manipular la esfera de los político [...]. Esto induce a pensar que en en la sociedad norteamericana se está creando una división cada vez más marcada entre millonarios intelectuales y proletarios intelectuales, división que es reforzada por los esquemas de utilización de los medios de comunicación en una forma que parece acentuarse más y más a medida que pasan los años [p. 256].

A estas críticas y cuestionamientos se han sumado muchísimas más desde diferentes ámbitos como el de algunos políticos, ${ }^{7}$ de la filosofía, ${ }^{8}$

' Por ejemplo, el ex presidente mexicano Miguel de la Madrid al expresar que "parece que la mercadotecnia de los publicistas oscurece la política y el debate de ideas, y eso es abaratar la política", por lo que prefiere "la discusión de conceptos, ideas y propuestas a los spots; no creo que a los candidatos haya que venderlos como si se tratara de jabones o pasta de dientes".

${ }^{8}$ El epistemólogo Karl Popper - uno de los fundadores de la Sociedad Mont Pèlerin, impulsora de la economía de mercado- en uno de sus últimos trabajos escribe con alarma 
pero, sobre todo, analistas políticos y de la comunicación en una cantidad que hace imposible presentar más que algunos casos con distintas argumentaciones. Así, Pratkanis y Aronson plantean que se está ante "el dilema esencial de la democracia moderna" por la contradicción entre la creencia en el intercambio de ideas y la discusión por un lado, y la utilización de "recursos de persuasión simplistas y en un razonamiento limitado", por el otro, lo que rompe con la idea de "concebirnos como animales racionales" para ser realmente "animales racionalizadores" porque "intentamos parecer razonables tanto ante nosotros mismos como ante los demás". Consideran también que la persuasión "puede tener calamitosas consecuencias para la democracia" por la utilización de técnicas cada vez más elementales y burdas, que favorecen una cada vez menor información, el aumento del escepticismo y la promoción de una espiral de ignorancia (Pratkanis y Aronson: 56, 57, 356).

Autores como Mouchon consideran que las críticas se centran en la ya indicada espectacularización de la política, el reemplazo de ideas por imágenes, y la utilización de encuestas como una forma moderna de gestación de opiniones colectivas (Mouchon, 1999: 13-17), y politólogoscomunicólogos como Landi agregan los cambios que se producen en la misma política:

[...] otra cosa eran los tiempos de la cultura letrada; ahora todo se vuelve más soft, ficcional y manipulable emocionalmente [...]. Por todas estas razones, la discusión sobre la televisión y el futuro de nuestras democracias interroga no sólo las relaciones de los medios con un determinado régimen institucional, sino también - y más inquietantemente- con las actuales características de la política como tal [Landi, 1991: 32-34].

Por eso es que Schenk entiende que "la comunicación política se ha convertido en objeto central de la investigación en la ciencia política", y citando a Langerbucher reitera lo ya mencionado acerca de la "despolitización" de los espectadores y su pregunta irónica de "cuánta ignorancia política aguanta una democracia y bajo qué condiciones" (Schenk, 1991: 48 y 50$)$.

Por su parte Sartori, en la tercera parte de su libro ¿Y la democracia? analiza las limitaciones de ésta —cuando la televisión fabrica una opinión que en definitiva la vacía- y la validez restringida de los sondeos, destaca el escaso conocimiento y significación que ofrecen las informaciones televisivas (al priorizar el "pseudoacontecimiento"), y critica la reducción de las noticias a lo que mueve sentimientos y emociones, en un contexto

que "la televisión se ha convertido en un poder demasiado grande para la democracia; ninguna democracia puede sobrevivir si no se pone fin al abuso de ese poder" (citado por Ferrer, 1999: 13). 
donde "en suma, lo visible nos aprisiona en lo visible", etcétera. Todo con ejemplos que toma del manejo actual de los medios acerca de la "realidad", reforzando lo ya sobradamente demostrado acerca de la desinformación, distorsión de la realidad, creación de personalidades con lenguajes ambiguos, emotivización de la política, homogeneización de modelos de vida y de gustos, fragmentación del mundo y de la realidad, etcétera.

Sartori hace además una afirmación epesimista o real? con importantes connotaciones para lo que es política y democracia:

En este trabajo, he insistido en la noción de animal simbólico porque no postulo que el hombre sea un animal racional. Su racionalidad presupone un lenguaje lógico (no sólo un lenguaje emotivo) y un pensamiento abstracto que se desarrolla deductivamente, de premisa a consecuencia. Por consecuencia, nuestra racionalidad es una potencialidad y, asimismo, un tener que ser, difícil de lograr y fácil de perder; es sólo una parte de nuestro ser. Pero es la condición sine qua non, la condición imprescindible, la condición necesaria. Y, sin embargo, el animal racional está siendo atacado profundamente, más de cuanto lo ha estado nunca [Sartori, 1998: 132].9

\section{Para continuar...}

Por supuesto, en lo aquí planteado no se agota una problemática tan contemporánea como vasta y compleja, de la que sólo se esbozaron sus líneas centrales, pero no únicas, quedando muchas otras para su elaboración y continuación inevitables. Entre ellas - algo muy visible en estos tiempos- el análisis permanente de un manejo mediático respecto a las circunstancias políticas, sociales y económicas que sigue estando en defensa del poder constituido y de sus intereses, más allá de que, a diferencia de un pasado reciente, pretende tomar formas aparentemente más abiertas a posturas diversas y no unilaterales. ${ }^{10}$

${ }^{9}$ Este mismo autor reitera y amplia su postura en un reportaje periodístico posterior, donde categóricamente señala que "el uso de la publicidad política corrompe la cultura democrática" y "habla de su pobreza", por lo que en muchos países democráticos "se permite la propaganda electoral, pero no los spots" (Gran Bretaña, Alemania, Francia, Suecia y Noruega, aunque esto no cambia mucho la situación) (Beltrán del Río y Jáquez, 1999: 18-22). A la pregunta de qué pasa con los programas de los partidos con la videopolítica, Sartori considera que "desaparecen al ser sustituidos por ataques personales y por la política basada en personalidades. El componente ideológico de la política tiende a esfumarse en la televisión. No hay tiempo para eso en la televisión, donde todo debe ser breve. Ahí, la forma prevalece sobre la sustancia".

${ }_{10}$ Así como en México y algunos otras sociedades, la publicidad electoral ya no es exclusiva de un solo partido como lo fue hace poco tiempo, en algunos medios se acepta una relativa pluralidad de opiniones que, sin embargo, está todavia muy lejos de una real y verdadera democracia mediática. 
No obstante, el problema central no se ha modificado en tanto, de manera latente como manifiesta, persiste la idea de política y de democracia aquí cuestionadas, muy diferente a una real, efectiva y participativa. Una idea de ambas que refuerza el concepto de que es la forma preferida para el mantenimiento del actual sistema de dominación, como en este artículo se pretende haber demostrado.

Claro que para un cambio verdadero se requieren medios con una idea diferente acerca de su papel a la que tienen los actuales, lo cual constituye, seguramente una utopía en los tiempos actuales, por lo cual, más allá de pensar en sus posibles características -que algunos pueden llegar a tener, aunque seguramente no los de mayor alcance-, puede y debe vigorizarse una perspectiva crítica respecto al actual control y manejo mediático.

\section{Bibliografia}

Alazakri, C. (1999), entrevista para La Jornada, México, 11 de septiembre.

Alfaro, R. (1994), "De las culturas populares a las transformaciones políticas", en Entre puiblicos y ciudadanos, Calandria, Lima, pp. 73-100.

- (1995), "Descifrando paradojas ciudadanas: una mirada cultural a la políti$\mathrm{ca}^{\prime}$, en Los medios, nuevas plazas para la democracia, Calandria, Lima, pp. 109-131.

Amin, S. (2003), "La ideología estadounidense", en La Jornada, México, 14 de junio.

Arredondo, P. (1990), "Medios de comunicación y procesos electorales. El caso de los noticieros de televisión", en Comunicación y Sociedad (8), Universidad de Guadalajara, pp. 11-41.

Beltrán del Río, P. y A. Jácquez (1999), "La videopolítica, producto de la pobreza de la cultura democrática: Giovanni Sartori”, en Proceso, núm. 1189, México, 15 de agosto.

Brünner, J. J. (1997), "Política de los medios y medios de la política: entre el miedo y la sospecha", en Dia-logos de la Comunicación (49), 9-22, Lima.

Debord, G. (1999), La sociedad del espectáculo, Pre-Textos, Valencia.

De la Madrid, M. (1999), La Jornada. México, 21 de septiembre.

Diario La Jornada (2003a), "Necesario, crear métodos transparentes para gobernar, plantea Woldenberg", México, 19 de febrero.

Etcétera (2004), núm. 42 y 43, 19 de febrero.

Ferrer, E. (1999), "Privilegios, poderíos y riesgos de la televisión", en La Jornada, México, 18 de septiembre.

Freud, S. (1976), "El malestar en la cultura", en Obras completas, t. XXI, Amorrortu, Buenos Aires.

Godinez, R. (2000), "Caminos, razones y estrategias de la mercadotecnia mediática de Vicente Fox", en Revista Mexicana de Comunicación (65), 12-15, México.

González Casanova, P. (2003), "Vivimos ahora el 'neoliberalismo de guerra general'", en La Jornada, México, mayo. 
Grossi, G. (1985), "La comunicación política moderna: entre partidos de masas y 'mass-media', en M. De Moragas (ed), Sociología de la comunicación de masas. IV. Nuevos problemas y transformación tecnológica, Gustavo Gili, Barcelona, pp. 144-164

Guinsberg, E. (1987), Publicidad: manipulación para la reproducción, Plaza y Valdés/uam-Xochimilco, México.

- (1988), Control de los medios, control del bombre. Medios masivos y formación psicosoctal, $2^{2}$ ed., Pangea/UAM-Xochimilco, México.

- (2002a), "El control social en 'tiempos de guerra", en Anuario de Investigación 2001, vol. II, Departamento Educación y Comunicación, UAMXochimilco, México, pp. 61-74.

- (2002b), "Aportes psicoanalíticos para el estudio de los procesos de recepción de los medios masivos", en Subjetividad y Cultura (18), México, pp. $27-45$.

- (2003), "El control social en 'tiempos de guerra', un año después", en Anuario de Investigación 2003, vol. I, Departamento Educación y Comunicación, UAM-Xochimilco, México, pp. 85-98.

314 (2004a), "Los medios masivos como calmantes", en Texto Abierto (5), Universidad Iberoamericana, León, pp. 11-44.

(2004b), "Protagonismo de los medios, limitaciones del pensamiento crítico", en Investigación de la comunicación, AMIC, México.

- Matrajt Campuzano (2001), "Subjetividad y control social: un tema central de hoy y siempre", en Subjetividad y Cultura (16), México, pp. 7-26.

Holzchuher, L. (1966), Psicología de la publicidad, Rialp, Madrid.

Iyengar, S., M. Peters, y D. Kinder, (1986), "Demostraciones experimentales de las consecuencias 'no tan mínimas' de los programas informativos de la televisión", en D. Graber (comp..), El poder de los medios en la política, Grupo Editor Latinoamericano, Buenos Aires, pp. 71-78.

- Klein, N. (2001), No logo, Paidós, Barcelona.

Krausze, E. (2004), "Para salir de Babel", en Letras Libres (65), México, mayo.

Kurnitzky, H. (1998), Vertiginosa inmovilidad, Blanco y Negro, México.

Landi, O. (1991), "Videopolítica y cultura”, en Diâ-logos de la Comunicación (29), Felafac, Lima.

Lechner, N. (1997), "El malestar con la política y la reconstrucción de los mapas políticos', en 'Winocur, R. (comp.), Culturas políticas a fin de siglo, Juan Pablos/Flacso, México, pp. 15-35.

Letras Libres (2004), 65, México, mayo.

Lins da Silva, C. (1991), "Industria de la comunicación: personaje principal de las elecciones presidenciales brasileñas de 1989", en Dia-logos de la Comunicación (29), Felafacs, Lima, pp. 56-60.

Martínez, O. (1999), "Televisión, política, imagen y marketing", Revista Mexicana de Comunicación (58), México abril-junio, pp. 4-5.

Mouchon, J. (1999), Politica y medios. Los poderes bajo influencia, Gedisa, Barcelona.

Manheim, J. (1983), “¿Podrá la democracia sobrevivir a la televisión?', en La ventana electrónica. Tv y comunicaciōn, Eufesa, pp. 251-260, México.

Monsiváis, C. (1997), "De los sentimientos electorales”, en Proceso, núm. 1080, México. 
Oliva Posadas, J. (2002), "Democracia y autoritarismo", en La Jornada, México, 2 de septiembre.

Pratkanis, A. y E. Aronson (1994), La era de la propaganda. Uso y abuso de la persuasión, Paidós, Barcelona.

Ramonet, I. (1998), "El pensamiento único", en Le Monde Diplomatique, pensamiento critico vs. Pensamiento único, Temas de Debate, Barcelona, pp. 1517.

(2003), "Información y democracia en la era de la globalización", sitio web Rebelión, 8 de diciembre.

Roy, A. (2003), "Democracia imperial instantánea", en La Jornada, núm. 287, suplemento Masiosare, México, 22 de junio.

Saramago, J. (2003,), La Jornada, México, 15 de mayo.

Sarmiento, S. (2004), “'Dialogar en los medios?”, Letras Libres, núm. 65, pp. 36-38, mayo.

Sartori, G. (1998), Homo videns. La sociedad teledirigida, Taurus, Madrid.

Schenk, M. (1991), "Comunicación política masiva: ¿efecto a pesar de poca participación? Nuevas estrategias de persuasión", en Dia-logos de la Comunicación, núm. 29, Felefacs, Lima, pp. 48-55.

Sen, A. (2004), "El ejercicio de la razón pública", en Letras Libres, núm. 65, México, pp. 12-20, mayo.

Valdez Zepeda, A. (1999), "La mecadotecnia política en México. La emergencia de un campo académico" en Comunicación y Sociedad (36), Guadalajara, p. 153-169.

- (2000), "Mercadotecnia política al servicio de la democracia". Revista Mexicana de Comunicación, (66), México, pp. 7-12, noviembre-diciembre.

- (2002), "El futuro de la mercadotecnia política", en Revista Mexicana de Comunicación, núm. 77, México, septiembre-octubre, pp. 48-51.

- A. Ibarra (2004.), "Tecnomarketing político", Revista Mexicana de Comunicación, núm. 85, México, febrero-marzo, pp. 50-51.

Vázquez Robles, G. (1988), "Comunicación y marketing político", en Revista Mexicana de Comunicación, núm. 53, México, pp. 12-17.

Zócalo (2004), núm. 50, México, abril, p. 50. 